\title{
Optimizing Antimicrobial Therapy of Sepsis and Septic Shock: Focus on Antibiotic Combination Therapy
}

\author{
Gloria Vazquez-Grande, MD ${ }^{1}$ Anand Kumar, MD² \\ ${ }^{1}$ Section of Critical Care Medicine, University of Manitoba, Winnipeg, \\ Manitoba, Canada \\ 2 Section of Critical Care Medicine and Section of Infectious Diseases, \\ Department of Medicine, Medical Microbiology and Pharmacology/ \\ Therapeutics, University of Manitoba, Winnipeg, Manitoba, Canada \\ Address for correspondence Anand Kumar, MD, Section of Critical \\ Care Medicine and Section of Infectious Diseases, Department of \\ Medicine, Medical Microbiology and Pharmacology/Therapeutics, \\ University of Manitoba, Winnipeg, Manitoba, Canada \\ (e-mail: akumar61@yahoo.com).
}

Semin Respir Crit Care Med 2015;36:154-166.

\begin{abstract}
There has been little improvement in septic shock mortality in the past 70 years, despite ever more broad-spectrum and potent antimicrobials. In the past, resuscitative elements have been the primary area of clinical septic shock management and research. The question of the optimal use of antimicrobial therapy was relatively ignored in recent decades. This review explores the pathophysiology of sepsis in an attempt to produce a better understanding and define key determinants of antimicrobial therapy response in septic shock. Optimizing existing antimicrobials delivery can drive significant improvements in the outcome of sepsis and septic shock. Inappropriate antimicrobial selection and dosing or delays in the administration substantially increase mortality and morbidity in life-threatening infections. Definitive combination therapy (where a pathogen known to be susceptible to a given agent is additionally covered by another agent) remains controversial. Although some in vitro studies, animal models, and clinical studies of infection including endocarditis, gram-negative bacteremia, and

Keywords

- septic shock

- life-threatening infection

- antibiotic

- combination therapy

- survival neutropenic infections have supported combination therapy, the potential clinical benefit in other severe infections has been questioned. Several meta-analyses have failed to demonstrate improvement of outcome with combination therapy in immunocompetent patients with sepsis and/or gram-negative bacteremia. These meta-analyses did not undertake subgroup analyses of the septic shock population. This article reviews the existing evidence supporting combination therapy for severe infections, sepsis, and septic shock.
\end{abstract}

Severe sepsis and septic shock with sepsis-associated multiple organ failure represent the major causes of infection-associated mortality and remain the most common cause of death in intensive care units (ICUs) of developed countries. They account for 10 to $15 \%$ of all ICU admissions and $25 \%$ of sepsis cases ${ }^{1}$; up to 50 to $75 \%$ of severe sepsis cases progress to septic shock. ${ }^{2}$ Septic shock alone represents 5 to $8 \%$ of all ICU admissions. ${ }^{3}$

Historically, the mortality associated with sepsis and septic shock has been $\sim 50$ to $75 \%{ }^{4-6}$ This decreased after the development of modern antimicrobial therapies, starting with penicillin in the early 1940s. Since then sepsis-associated mortality has fallen to the 30 to $50 \%$ range. ${ }^{4,5}$

Since the development of modern antimicrobials, bacterial pathogens have continuously evolved under their selective pressure. There has also been a gradual increase in the incidence of sepsis over the intervening decades. ${ }^{7}$ Current estimates suggest a doubling of total cases of severe sepsis in United States by 2050 (from the actual 800,000 cases per year
Issue Theme Antimicrobial Resistance: Management of Superbugs; Guest Editor, David L. Paterson, MBBS, PhD, FRACP, FRCPA
Copyright (C) 2015 by Thieme Medical Publishers, Inc., 333 Seventh Avenue, New York, NY 10001, USA. Tel: +1(212) 584-4662.
Dol http://dx.doi.org/ 10.1055/s-0034-1398742. ISSN 1069-3424. 
to 1.6 million cases), with a less than proportionate increase in population of only $33 \%$ during the same period. ${ }^{8}$

Despite major advances in technology and a constant improvement and refinement of our understanding of sepsis pathophysiology, numerous clinical trials have failed to produce any new drugs with consistent beneficial effects on this patient population. ${ }^{9,10}$ Part of the reason for the failure to develop effective novel therapies may be a fundamental misunderstanding of the pathophysiology of septic shock. ${ }^{11}$

\section{The Immunologic Model}

The currently accepted immunologic paradigm of sepsis suggests that this disorder is present when the activation of the systemic inflammatory pathways is triggered by infection. ${ }^{12,13}$ The infection initiates an immunologic response (inflammatory cytokine and eicosanoid/coagulation cascade) that propagates independently of the underlying infectious trigger. ${ }^{14,15}$ This view of sepsis is reflected in the classic figure by Bone and colleagues ( $\mathbf{- F i g . 1}$ ). ${ }^{12}$ The figure indicates that sepsis is defined by the co-occurrence of infection and systemic inflammatory response syndrome (SIRS), a syndrome that is only indirectly related to the underlying infection. There is no clear suggestion (in the figure) that uncontrolled infection drives the development of SIRS.

This model suggests that progression of sepsis occurs as a consequence of inflammatory cellular signaling and a counter-inflammatory (immunoparalytic) response, ${ }^{16,17}$ despite the rapid elimination of the pathogen through administration of cidal antimicrobial therapy ${ }^{14}$ (-Fig. 2). In this view, sepsis, severe sepsis, and septic shock are related disorders of increasing severity, sharing an underlying pathophysiology involving direct endogenous mediator-driven cellular dysfunction and injury.

Under this model, septic shock is considered to be a consequence of the underlying cellular injury induced by the inflammatory mediators rather than by a clinical entity with different and distinct pathogenesis and pathophysiology. If this view of sepsis is wrong or incomplete, this may

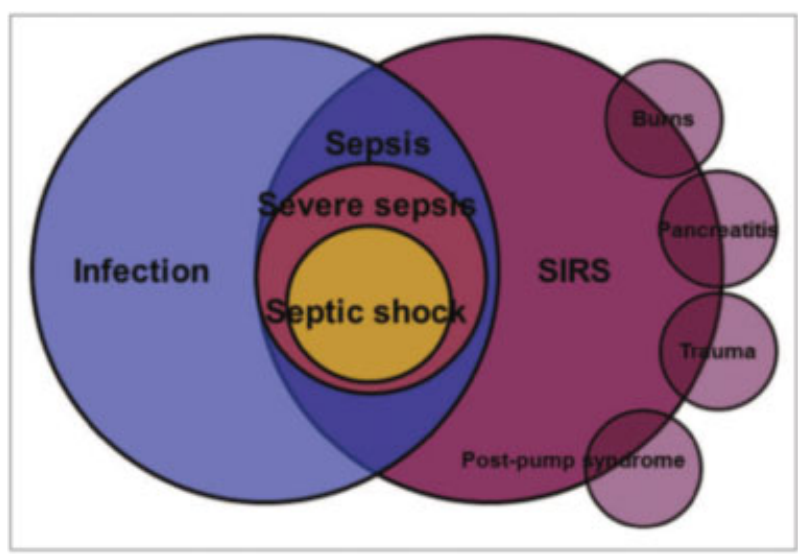

Fig. 1 SIRS, sepsis, severe sepsis, and septic shock. SIRS, systemic inflammatory response. Adapted with permission from Bone et al. ${ }^{12}$ See text for explanation.

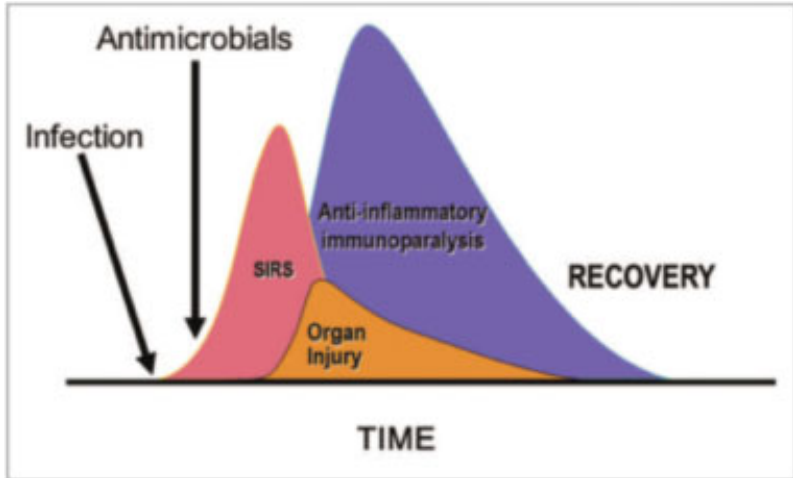

Fig. 2 Immunologic view of sepsis and septic shock. SIRS, systemic inflammatory response. Adapted with permission from van der Poll and van Deventer. ${ }^{14}$ See text for explanation.

explain the reason why immunomodulatory therapies that were developed based on this model failed to improve outcomes in clinical trials. ${ }^{18}$

A key deficiency of this immunologic paradigm of sepsis is that most pathogens cannot be eliminated quickly from the patient, despite the use of cidal antimicrobial therapy. ${ }^{19-23}$ Pathogens likely persist over time, maintaining an inflammatory potential. If immunomodulatory therapies (most of which are immunosuppressive) are initiated, clearance of the pathogen burden may even be slowed down despite use of cidal antimicrobials.

\section{The Classic Paradigm: Microbiologic Primacy}

Another view of septic shock derives from the classic model where the infection is the key driving element of sepsis (-Fig. 3). ${ }^{11}$ The septic process starts with a focus of infection, where the organism replicates, increasing the microbial load over time. The pathogens release endo- and exotoxins (toxic burden), which stimulate the production of the endogenous mediators of the inflammatory cascade. The central aspect of the microbiologic paradigm is that the microbial load drives

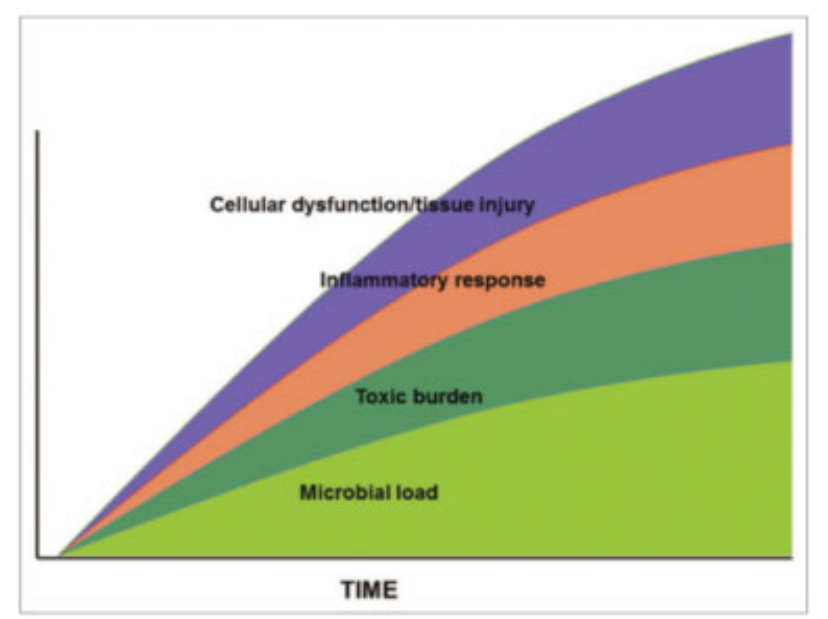

Fig. 3 Microbiologic view of sepsis and septic shock. Reproduced with permission from Kumar. ${ }^{11}$ See text for explanation. 
the downstream responses. Thus, the elimination of the underlying infection should terminate the inflammatory cascade and limit tissue injury and organ dysfunction. This model forms the basis of standard antimicrobial therapy in sepsis and septic shock.

However, this model has a key deficiency in that it fails to recognize a key element of septic injury progression, the occurrence of irreversible shock, as originally described by Wiggers in $1950 .{ }^{24}$ The concept of irreversible shock suggests that shock can only be tolerated for a limited time regardless of the etiology. If the condition driving shock is not directly addressed within a short period of time, shock will become irreversible, with inevitable progression to death. This is directly associated with the idea of the "golden hour," first demonstrated in the context of hemorrhagic shock in trauma, but applicable to other shock states. A corollary of this concept suggests that mortality will not be improved without early definitive elimination of the underlying source of hemodynamic instability (e.g., thrombolysis, ${ }^{25}$ angioplasty, ${ }^{26}$ or definitive repair/control of a bleeding lesion causing hypovolemic shock ${ }^{27}$ ). With respect to mortality reduction, it is not sufficient to provide only supportive care.

\section{A Composite Model: Integrating Infection and Shock}

If we consider septic shock under an alternative composite perspective, the presence of shock becomes the key driver in the genesis of irreversible organ injury. In this paradigm of septic shock, the underlying source of shock is the microbial load. Thus, the faster you reduce the microbial load to a subcritical threshold, after the onset of persistent or recurrent hypotension, the higher the survival.

This model construct is similar to the microbial paradigm, with two additions (- Fig. 4). ${ }^{11}$ The shock threshold line is the point at which inflammatory mediator-associated cellular dysfunction manifests as septic shock (which is highly variable between individuals). Once that point has been passed, persistent/recurrent hypotension sets the patient on the path to irreversible organ injury and death. ${ }^{11}$

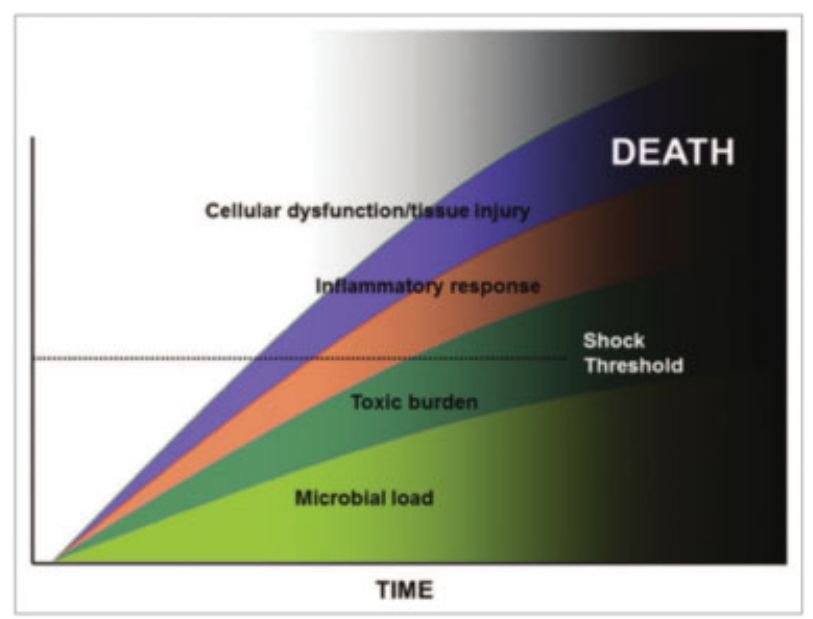

Fig. 4 Composite view of sepsis and septic shock. Reproduced with permission from Kumar. ${ }^{11}$ See text for explanation.
The optimal therapy in this paradigm of septic shock is to rapidly reduce the microbial load to minimize the time that inflammatory stress is sufficient to sustain shock (- Fig. 5). ${ }^{11}$ This should limit the risk of reaching the individually indeterminate pathophysiologic point at which recovery is no longer possible.

This composite model has two major pathophysiologic implications. First, septic shock and sepsis without shock are different diseases rather than the same syndrome with differing severity. The evidence for this proposal lay in stark clinical features (hypotension, lactic acidosis, substantial exhaustion of compensatory physiologic responses) and high $(>50 \%)$ mortality in septic shock, in contrast to the milder clinical features and lower mortality $(\sim 15 \%)$ of sepsis or severe sepsis, ${ }^{28}$ the different profiles of inflammatory mediators in these conditions ${ }^{29,30}$ and evidence of immune dysfunction in septic shock compared with sepsis without shock. $^{31}$

The second major implication is that delays in initiation of appropriate antimicrobial therapy is associated with a higher microbial load, ${ }^{32-34}$ and that organism burden is associated with increased morbidity and mortality in serious infections. $^{6,35-41}$ Hence, early appropriate antimicrobial therapy with acceleration of the speed of bacterial clearance should be associated with both improved morbidity and mortality. ${ }^{42}$

\section{Optimizing Pathogen Clearance}

As central corollary of this composite/integrative model of septic shock is that the key determinant of outcome in septic shock is accelerated pathogen clearance. - Table $\mathbf{1}$ lists the antimicrobial determinants of pathogen clearance in serious infections including septic shock. ${ }^{11}$ Each factor has a potential impact on speed of pathogen clearance in the clinical context.

This review will focus on antimicrobial optimization principles that underlay rapid reduction in the pathogen burden, particularly combination therapy as it relates to septic shock. Supplemental antimicrobial therapies (source control), antitoxin/immunomodulatory strategies and supportive measures will not be discussed in this review.

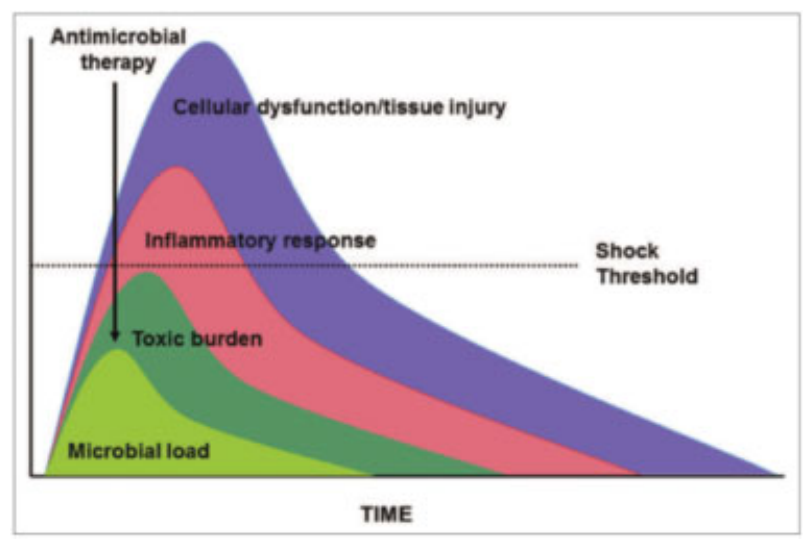

Fig. 5 Impact of appropriate antimicrobial therapy in sepsis and septic shock. Reproduced with permission from Kumar. ${ }^{11}$ See text for explanation. 
Table 1 Antimicrobial determinants of pathogen clearance in septic shock

\begin{tabular}{|l|}
\hline 1. Early antimicrobial therapy \\
\hline a. Initiate microbially appropriate therapy \\
\hline b. Ensure maximally rapid initiation (avoid delays) \\
\hline c. Utilize a loading dose when possible \\
\hline 2. Antimicrobial potency \\
\hline a. Ensure antimicrobial cidality \\
\hline b. Optimize pharmacokinetic indices \\
\hline i. Time-dependent agents \\
\hline ii. Concentration-dependent agents \\
\hline c. Utilize combination therapy with antimicrobials \\
possessing different mechanisms of action \\
\hline 3. Supplemental therapies \\
a. Source control \\
\hline
\end{tabular}

Source: Reproduced with permission from Kumar. ${ }^{11}$

\section{Early Antimicrobial Therapy}

Appropriateness of the initial empiric antimicrobial therapy, early administration without delays, and achievement of therapeutic levels as soon as possible (ideally after the first dose) are the three pillars of effective antimicrobial therapy. Application of these three principles will reduce the microbial burden, decreasing the risk of irreversible shock and death.

This approach is based on Paul Ehrlich's famous dictate: "Frapper fort et frapper vite" (i.e., "hit hard and hit fast"), stated in the 17th International Congress of Medicine in 1913.43

\section{Appropriate Empiric Antimicrobial Therapy}

Although data in sepsis without shock are inconsistent, ${ }^{44-48}$ empiric antibiotics should cover every reasonably likely pathogen, as failure to initiate antimicrobial therapy to which the pathogen is sensitive is associated with marked increases in mortality, especially in septic shock. ${ }^{49-55}$ Inadequate antimicrobial therapy is started frequently ${ }^{49,56}(15-35 \%)$, increasing mortality risk. Recent data suggest that inappropriate empiric antimicrobial treatment reduces survival fivefold in serious infections with septic shock. ${ }^{49}$

To broaden the spectrum of coverage of the empiric antimicrobial therapy, combination strategies should be used for the first few days, at least in patients with septic shock. However, empiric combination therapy must be adjusted to a narrower regimen in the first 72 hours if possible, to minimize selection pressure toward resistant organisms. There are no studies that have suggested that early narrowing of therapy is detrimental if the organism is identified or if the patient is responding well clinically. On the contrary, some studies have pointed to de-escalation of antimicrobial therapy associated with improved outcomes. $^{57-60}$

\section{Antimicrobial Delay}

Delay in the initiation of appropriate antimicrobial therapy has a substantial role in determining mortality in high-risk infections with a particularly strong association with septic shock. ${ }^{52,61-66}$ Delays are only inconsistently associated with mortality in bacteremia/candidemia and sepsis without shock. ${ }^{67-71}$

One major retrospective analysis of septic shock suggested that the delay in initial administration of effective antimicrobial therapy is the single strongest predictor of survival. ${ }^{72}$ Every hour of delay in appropriate antimicrobial administration, in the first 6 hours after hypotension is documented, decreases survival by $7.6 \%$. Despite this findings, the median time to deliver appropriate antimicrobial therapy in septic shock was 6 hours (although these data are now several years outdated) ( $\mathbf{- F i g . ~ 6 ) .}{ }^{72}$

Additional retrospective studies of human bacteremia, candidemia, septic shock, community-acquired pneumonia, hospital-acquired pneumonia, surgical infections, and meningitis with sepsis have confirmed that the mortality in these septic conditions is increased with significant delays in antimicrobial administration. ${ }^{52,63,64,66,73-76}$ The impact on outcome of speed of appropriate empiric antimicrobial administration in relationship with other therapies such as fluid resuscitation suggests that greater remediable deficiencies (and greater potential for improvement in care) may lie with the appropriate early antibiotic administration. ${ }^{72,77,78}$

In view of these data, intravenous administration of broadspectrum antimicrobials should be initiated as rapidly as possible in response to clinical suspicion of infection in the presence of persistent hypotension. Obtaining laboratory test or cultures should never delay antimicrobial therapy.

\section{Loading Doses}

Early appropriate antimicrobial therapy is the central element in management of septic shock, but clearance of

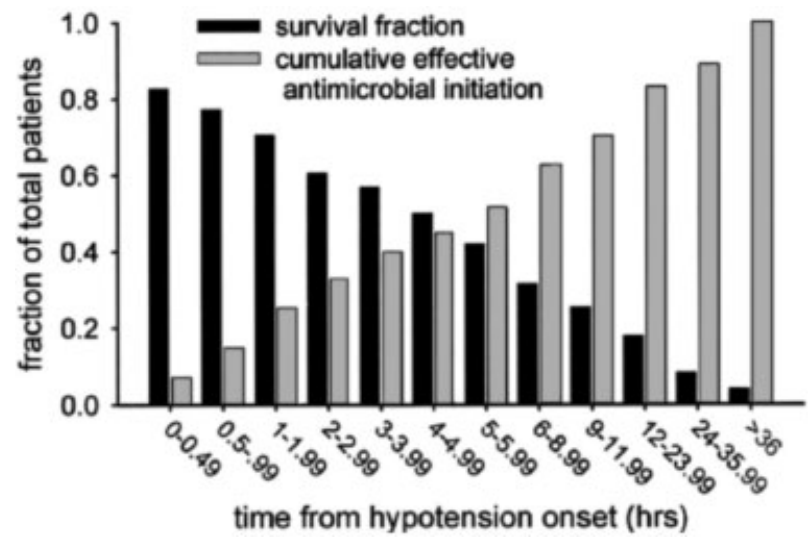

Fig. 6 Cumulative effective antimicrobial initiation following onset of septic shock-associated hypotension and associated survival. The $x-$ axis represents time (hour) following first documentation of septic shock-associated hypotension. Black bars represent the fraction of patients surviving to hospital discharge for effective therapy initiated within the given time interval. The gray bars represent the cumulative fraction of patients having received effective antimicrobials at any given time point. Reproduced with permission from Kumar et al. ${ }^{72}$ 
pathogens will not begin until therapeutic levels of the antimicrobials in the circulation are achieved.

The markedly increased volume of distribution that many antimicrobials exhibit (i.e., $\beta$-lactams, aminoglycosides, vancomycin, teicoplanin, and colistin) can result in failure to achieve therapeutic levels initially with standard dosing approaches. ${ }^{79-82}$ An emerging body of literature suggests that loading doses of some antimicrobials can potentially yield improved clinical outcomes. ${ }^{79,80,83}$

\section{Potency of Antimicrobial Therapy}

According to Ehrlich's dictate on optimizing therapy of serious infections, the first principle was to "hit it hard." This principle has many implications in regard to antimicrobial strategy. It suggests that highly potent antimicrobial regimens that provide the most rapid clearance of pathogens are preferred (-Fig. 7). ${ }^{11}$ It also suggests that pharmacokinetic optimization of antimicrobial dosing is a requirement for ideal therapy. Further to the extent that combination therapy has been shown to accelerate pathogen clearance in some models of infection, ${ }^{84}$ this principle implies that improved survival should result. In the case of septic shock, more rapid pathogen clearance is expected to lead to less release of endogenous mediators, more rapid resolution of hemodynamic instability, and improved survival.

\section{Cidal versus Static Therapy}

Although cidal therapy, by definition, should provide more rapid clearance of pathogens, clinical studies generally suggest a lack of clinical superiority over static therapy in most infections. ${ }^{85,86}$ There are a paucity of data in this issue regarding septic shock. The best known study that has addressed the issue of the importance of cidality in lifethreatening infections is the classic study of bacterial meningitis by Lepper and colleagues in $1951 .^{87}$ This study showed inferior outcomes with chlortetracycline which is bacteriostatic compared with penicillin, a cidal drug. In recent years, few studies have compared the efficacy of well-established

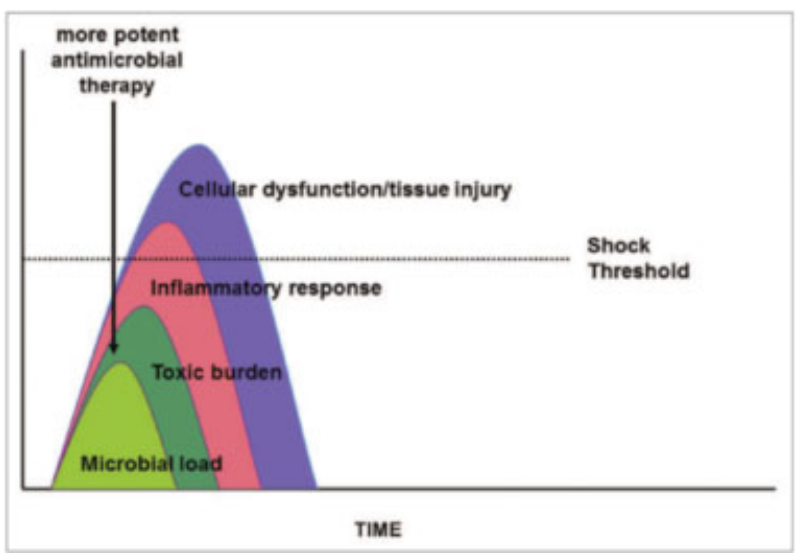

Fig. 7 Impact of more potent antimicrobial therapy in sepsis and septic shock. Reproduced with permission from Kumar. ${ }^{11}$ See text for explanation. cidal versus static agents in serious infections that may be associated with sepsis and septic shock.

One randomized controlled study of anidulafungin, a cidal antifungal echinocandin, demonstrated superiority over fluconazole, a static triazole, in invasive candida infections. ${ }^{22}$ Other studies showed that higher cidal activity of antibiotic regimens are associated with better clinical cure rates in bacterial endocarditis, ${ }^{88,89}$ osteomyelitis, ${ }^{90}$ and in neutropenic gram-negative bacteremia. ${ }^{91}$

Although nominally a cidal agent, vancomycin has relatively weak bacterial killing activity relative to antistaphylococcal penicillins for methicillin-sensitive S. aureus (MSSA) in time kill studies. ${ }^{92}$ Accordingly, retrospective studies have shown that vancomycin yields inferior clinical responses and/ or survival than anti-staphylococcal $\beta$-lactams in patients with MSSA bacteremic infections including pneumonia. ${ }^{92-94}$ Notably, the bacteriostatic agents, quinupristin/dalfopristin (a streptogramin) and linezolid (an oxazolidinone), appear to be no more effective than vancomycin for therapy of serious $S$. aureus infections. ${ }^{95,96}$ The cidal lipopeptide, daptomycin, in contrast, tends to be superior to vancomycin and comparable to $\beta$-lactams in the treatment of bacteremic $S$. aureus infections. $^{97}$

Overall, the available evidence supports the potential superiority of cidal therapy in life-threatening infections. However, additional studies will be required to definitively address this question in septic shock where the difference should be most profound.

\section{Pharmacokinetic Optimization}

A substantial body of literature suggests that optimization of dosing strategies can improve pathogen clearance and clinical responses in infection. However, to date, data on the impact of pharmacokinetic (PK) optimization on mortality in serious infections, particularly septic shock, remain sparse.

\section{Time-Dependent Killing Agents}

For $\beta$-lactam antibiotics, the key PK parameter for optimization of pathogen clearance is the fractional time above the minimal inhibitory concentration ( $\mathrm{fT}>\mathrm{MIC}$ ) of the pathogen. There are relatively few studies that examine the role of $\mathrm{fT}>\mathrm{MIC}$ in serious human infections. They suggest that high fT $>$ MIC ( $>60-100 \%$ ) is associated with better bacterial eradication and clinical cure. ${ }^{98,99}$

Continuous infusion of certain antibiotics, which generates $100 \% \mathrm{fT}>$ MIC for sensitive pathogens, compared with intermittent administration (i.e., piperacillin-tazobactam, meropenem, ceftazidime), resulted in improved clinical cure, $^{100-103}$ shorter hospitalization, and lower mortality ${ }^{104}$ in the subset of the most critically ill patients, many of whom would have had septic shock.

At least two meta-analyses of continuous infusion of $\beta$ lactams in human infection have been published. ${ }^{105,106} \mathrm{Nei}-$ ther showed an overall beneficial effect of continuous infusion; however, both yielded intriguing insights. Each study commented on the trend toward greater beneficial effects in those studies with high baseline mortality risk, an 
observation that is congruent with our underlying hypothesis that the benefit of PK optimization of dosing strategies on mortality should exist primarily in septic shock.

As a whole, these data support the use of high-end daily dosing at short intervals or extended infusions and continuous infusions where possible. These data also suggest the need for studies of continuous infusion $\beta$-lactam therapy in the highest risk septic shock patients who are most likely to benefit.

\section{Concentration-Dependent Killing Agents}

For fluoroquinolones and aminoglycoside antibiotics, the key PK parameter for optimization of pathogen clearance is the area under the curve divided by the MIC of the pathogen normalized to 24 hours $\left(\mathrm{AUC}_{24} / \mathrm{MIC}\right)$, although peak/maximum concentration divided by the $\mathrm{MIC}\left(\mathrm{C}_{\max } / \mathrm{MIC}\right)$ is a closely related value. ${ }^{107-109}$

Experimental animal models and human studies suggest that an $\mathrm{AUC}_{24} / \mathrm{MIC}$ of $>87$ to 125 for fluoroquinolones (depending on the individual drug and clinical syndrome) during the course of therapy yields optimal pathogen clearance and clinical cure. ${ }^{107-109}$ Unfortunately, there are no human data linking fluoroquinolone PK indices to survival or mortality and no studies of septic shock have yet been reported. Similarly, peak/MIC ratios of $>10$ to 12 have been shown to be associated with improved clinical and microbiologic cure rates with aminoglycosides. ${ }^{110-112}$

Vancomycin is another antibiotic whose efficacy is most closely related to concentration-dependent pharmacokinetic indices. Retrospective studies of methicillin-resistant S. aureus (MRSA) bacteremia and pneumonia reported better microbiological and clinical outcomes in patients who had vancomycin $\mathrm{AUC}_{24} / \mathrm{MIC}$ of $400 .{ }^{113,114}$ This has been shown to be independently associated with survival in a retrospective study of MRSA septic shock. ${ }^{115}$

Antimicrobial pharmacokinetic indices have been linked to clinical and microbiologic response in a variety of studies, but the ones showing an association with survival are more limited. To the extent that such studies exist, they tend to show a survival advantage in critically ill patients, particularly in those with septic shock.

\section{Combination Therapy}

There are three major potential advantages of using combination anti-infective therapy for serious life-threatening infections. ${ }^{116}$ The most accepted one is that combination therapy increases the spectrum of coverage, allowing a higher probability of appropriate initial therapy, reducing mortality. ${ }^{78,117}$ This is the primary reason why initial empiric combination therapy is broadly utilized and specifically recommended in sepsis and septic shock clinical guidelines. ${ }^{78}$

Another potential advantage of combination therapy when compared with monotherapy is reduced risk for emerging of resistance during therapy. ${ }^{118-120}$ Similarly, potential additive or synergistic effect ${ }^{118,119}$ leading to more rapid pathogen clearance ${ }^{84,119,121,122}$ may translate into improved patient outcome and may be the most directly clinically relevant advantage of combination therapy.
Antimicrobial synergy, with increased bacterial clearance, has been best established for $\beta$-lactam/aminoglycoside combinations. ${ }^{123}$ It has also been described in $\beta$-lactam/fluoroquinolone combinations, ${ }^{124,125}$ and there are some data that suggest additive effects or even synergism for $\beta$-lactam/macrolides combination. ${ }^{126}$ There are also potential disadvantages related to combination therapy, such as increased risk for toxicity, higher costs, possible antagonism between specific drug combinations, and selection of resistant strains. ${ }^{127}$

Despite efforts to address the issue of whether two antimicrobials improve outcome in sepsis and septic shock compared with a single agent, the results of published clinical studies and meta-analyses on combination therapy for gramnegative bacteremia and/or sepsis are contradictory. The question has not been definitively answered.

In the meta-analysis of gram-negative bacteremia performed by Safdar and colleagues in 2004, ${ }^{128}$ an overall mortality benefit with combination therapy (odds ratio [OR], 0.96; 95\% confidence interval [CI], 0.7-1.32) was not found in the overall dataset. Several subgroup analyses were also performed to determine whether the findings would differ if trials were separated according to date of publication (i.e., before or after 1990, when more potent antimicrobials were made available) or study design (i.e., retrospective vs. prospective). Regardless of subset analyses, there remained no added benefit to combination therapy except in an analysis restricted to the five studies of Pseudomonas aeruginosa bacteremia. In that group, the summary OR was 0.5 (95\% CI, 0.32-0.79; $p=0.007$ ), suggesting a $50 \%$ relative reduction in mortality with the use of combination therapy. The authors noted, however, that the underlying populations in these studies varied considerably, and a sizeable proportion of patients were immune-compromised, making it difficult to apply the results to the general population.

The systematic review of randomized controlled trials performed by Marcus et al in 2011 also failed to demonstrate a benefit of combination therapy with $\beta$-lactam/aminoglycoside in a wide variety of infections. ${ }^{129}$ The meta-analysis performed by Paul and colleagues in $2004^{130}$ and the two Cochrane reviews performed by the same group in $2006^{131}$ and $2014,{ }^{132}$ have also failed to demonstrate evidence of improvement of outcome with combination therapy in immunocompetent patients with sepsis. Further, the addition of an aminoglycoside to a broad-spectrum $\beta$-lactam did not only fail to reduce the overall mortality in patients with gram-negative sepsis but was also associated with an increased risk for adverse events. ${ }^{132}$ Similarly, in 2003, the same group published a meta-analysis in neutropenic sepsis that suggested little incremental benefit of combination therapy of $\beta$-lactam and an aminoglycoside in this setting. ${ }^{133}$ Of note, none of these studies undertook an analysis in the subgroup of septic shock patients. Moreover, in the Cochrane review of 2006, a lack of benefit with combination therapy was more common among those studies with a structural bias (i.e., comparing a more potent $\beta$-lactam with a weaker $\beta$-lactam and a second agent).

Several studies have found that the efficacy of some antimicrobial therapies can be restricted to severely ill patients at high risk of death, particularly in severe pneumococcal pneumonia/ 
bacteremia $^{134-136}$ and gram-negative bacteremia. ${ }^{137,138}$ In the study by Rodríguez and colleagues in 2007 , a secondary analysis of a prospective observational cohort of community-acquired pneumonia who developed shock, concluded that combination therapy was associated with a significantly higher survival. ${ }^{136}$ Korvic et al and Hilf et al found similar results in gram-negative bacteremia with shock. ${ }^{137,138}$ These data suggest the possibility that the benefit in outcome of combination therapy in sepsis may only exist in severely ill patients, particularly those with septic shock.

The conflicting results addressing the question of the usefulness of combination therapy in sepsis might be explained by the heterogenic nature of the different studies, structural bias, and variations between patient characteristics, severity of infections, infection sites, causative bacteria, and antibiotic treatment. Many of these studies were observational (where selection bias and confounding by indication are difficult to avoid, especially with the use of relatively subjective criteria such as clinical response, rather than mortality). Another difficulty is that most randomized studies are designed to assess noninferiority (which means they have a structural bias in favor of showing equivalence between monotherapy and combination therapy). Moreover, those studies often do not compare the same antibiotic in monotherapy and in combination with a second agent. Usually, a more pharmcodynamically potent agent in monotherapy is compared to a combination of two weaker agents. In addition, randomized controlled trials often do not have sufficient numbers of a particular type of microorganism or a particular patient population (such as septic shock, a population that is often excluded) to allow robust subgroup analyses. Thus, synergy is difficult to rigorously assess in many individual studies.

Based on the possibility that any benefit in survival with combination therapy may be restricted to only the most critically ill subset of patients, we tested this hypothesis performing a stratified meta-analysis/meta-regression of 60 sepsis datasets (derived from 48 individual studies). ${ }^{139}$ The quality of the study was enhanced by splitting data from 12 studies into mutually exclusive groups of septic shock/critically ill and non-septic shock/non-critically ill and by excluding studies where a structural bias would favor an equivalence outcome (i.e., a highly potent $\beta$-lactam vs. a less potent $\beta$-lactam and a second agent). Studies of neutropenic sepsis were also excluded. Notably, the pathogen was required to be sensitive to both agents in the combination therapy group.

Although we found the same absence of significant benefit of combination therapy overall, stratification of the datasets by baseline (monotherapy) mortality risk showed a consistent substantial benefit in terms of clinical cure and survival with combination therapy in the most severely ill subset of patients (monotherapy risk of death $>25 \%$; OR, 0.51 ; $95 \% \mathrm{CI}$, $0.41-0.64 ; \mathrm{I}^{2}=8.6 \%$ ) (-Fig. $\mathbf{8}^{139,140}$ ). Of the 24 datasets derived from 12 studies that could be stratified by the presence of shock or critical illness, the septic shock/critically ill group demonstrated consistently better outcomes with combination therapy (OR, 0.49; 95\% CI, 0.35-0.70; $p<0.0001 ; \mathrm{I}^{2}=0 \%$ ) (- Fig. $\left.\mathbf{9}^{139}\right)$. This meta-regression indicated that the benefit found with combination therapy was only dependent on the risk of death in the monotherapy group (i.e., the severity of illness). This finding held when datasets were restricted to randomized controlled trials. These results also held in subgroups stratified by a variety of factors including organism, organism grouping (gram positive or negative), clinical syndrome, and supplemental antibiotic agent.

This study was followed by a large retrospective propensity-matched multicenter cohort study by our group, ${ }^{53}$ evaluating the therapeutic benefit of early combination therapy with at least two antibiotics with confirmed activity against the pathogen isolated in septic shock patients. Significant beneficial effects were observed in outcome, finding an improved 28-day survival (444 of 1,223 [36.6\%] vs. 355 of 1,223 [29\%]; hazard ratio $0.77 ; 95 \% \mathrm{CI}, 0.67-0.88 ; p=0.0002$ ) ( $\mathbf{- F i g . ~} \mathbf{1 0}^{53}$ ). Combination therapy was also associated with significant reductions in ICU (437 of 1,223 [35.7\%] vs. 352 of $1,223$ [28.8\%]; OR, 0.75; 95\% CI, 0.63-0.92; $p=0.0006)$ and hospital mortality (584 of 1,223 [47.8\%] vs. 457 of 1,223 [37.4\%]; OR, 0.69; 95\% CI, 0.59-0.81; $p<0.0001$ ). The beneficial impact of combination therapy applied to both grampositive and gram-negative infections but was restricted to $\beta$ lactam antibiotics in combination with aminoglycosides, fluoroquinolones, or macrolides. Notably, the most potent $\beta$-lactams (i.e., carbapenems, anti-pseudomonal third- and fourth-generation cephalosporins, $\beta$-lactamase inhibitor combinations) failed to demonstrate a benefit in outcome with combination therapy. ${ }^{53,141}$ This may be explained by their high cidality, as it is near maximal for most pathogens (fT > MIC 100\%). In this circumstance, the addition of a second drug may have little incremental benefit. Several additional recent retrospective studies show a benefit in survival of patients in septic shock and related critical conditions with combination therapy using antibiotics with different mechanisms of action. ${ }^{52,142}$

Although highly suggestive, these retrospective analyses cannot be considered definitive. While waiting for appropriately designed randomized controlled trials, combination of empiric antibiotic therapy for several days with two drugs of different mechanisms of action is appropriate for patients in septic shock. Monotherapy is reasonable for patients who are not critically ill and not at high risk of death.

\section{Conclusion}

Anti-infective therapy is the cornerstone of treatment for critically ill patients with sepsis and septic shock. The choice of initial empiric antimicrobial therapy is crucial in determining positive outcomes. The optimal selection of antibiotics depends on the local resistance epidemiology as well as individual risk factors for resistance, including recent antibiotic use, hospitalization, and previous colonization or infection with resistant strains. The speed with which appropriate antimicrobials are initiated is now well recognized as a crucial element in providing effective care of patients with all lifethreatening infections including septic shock. In addition, 


\section{Monotherapy mortality $>25 \%$}

\section{Monotherapy mortality $<15 \%$}

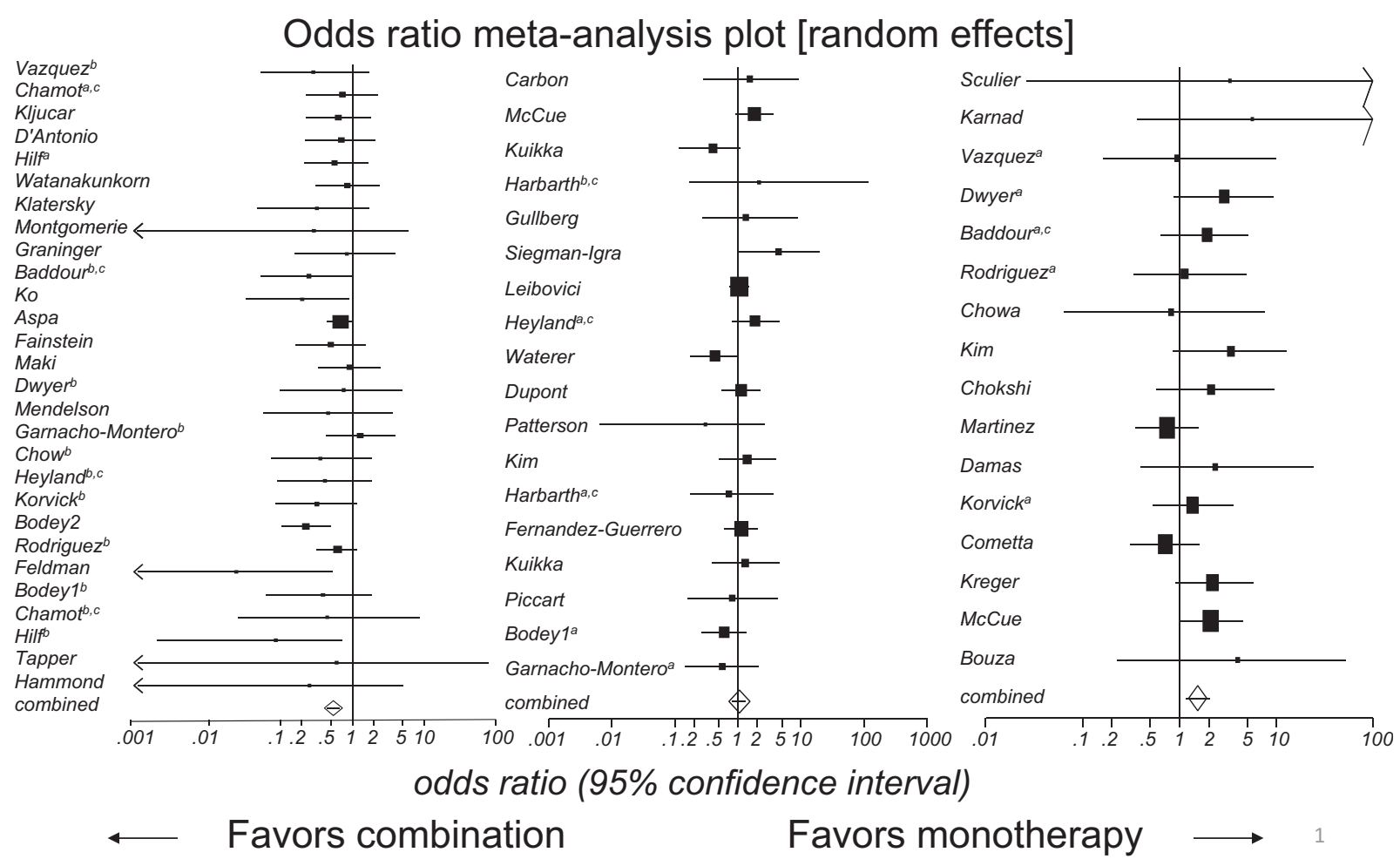

Fig. 8 Analysis of studies comparing combination antibiotic therapy with monotherapy for reducing mortality of life-threatening infections associated with sepsis. Note the gradual shift of the odds ratio from the right to the left as monotherapy mortality increases. The size of the squares is proportional to the reciprocal of the variance of the studies. ${ }^{a}$ Nonshock or noncritically ill stratified dataset. ${ }^{b}$ Shock or critically ill stratified dataset. ${ }^{\circ}$ Modified dataset provided by study authors. Adapted and reproduced with permission from Kumar et $\mathrm{al}^{139}$ (originally cited in Abad et $\mathrm{al}^{140}$ ).

maximization of cidality through pharmacokinetic optimization and combination therapy can be useful.

Several studies have attempted to answer the question of whether combination therapy improves outcomes in septic patients when compared with monotherapy. The data reviewed suggest that the question of whether combination therapy is beneficial may be outdated. The appropriate question may be under what circumstances combination therapy is beneficial.

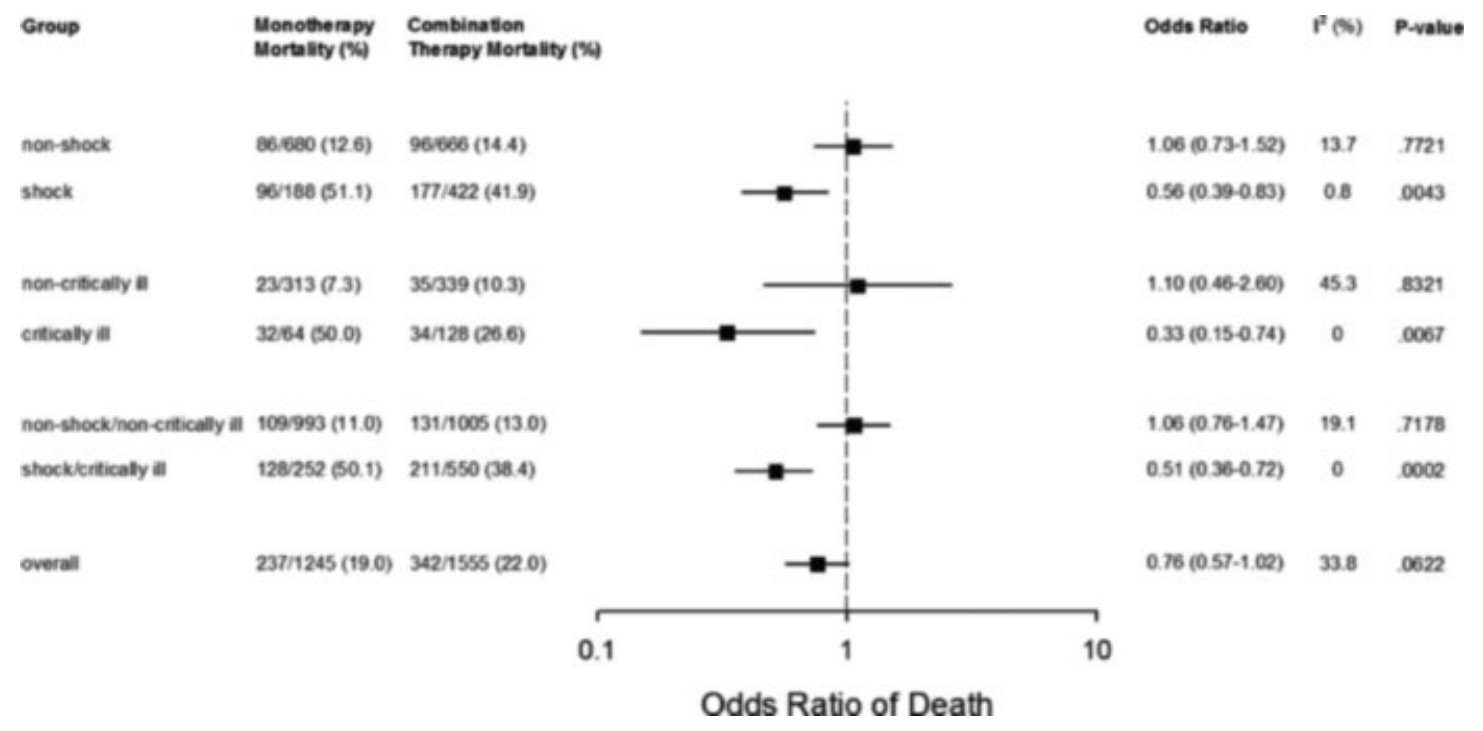

Fig. 9 Subset analysis comparing combination antibiotic therapy with monotherapy for reducing mortality of life-threatening infections associated with sepsis in shock/critically ill and nonshock/noncritically ill patient datasets (derived from 12 studies in which groups could be separated). Reproduced with permission from Kumar et al. ${ }^{139}$ 


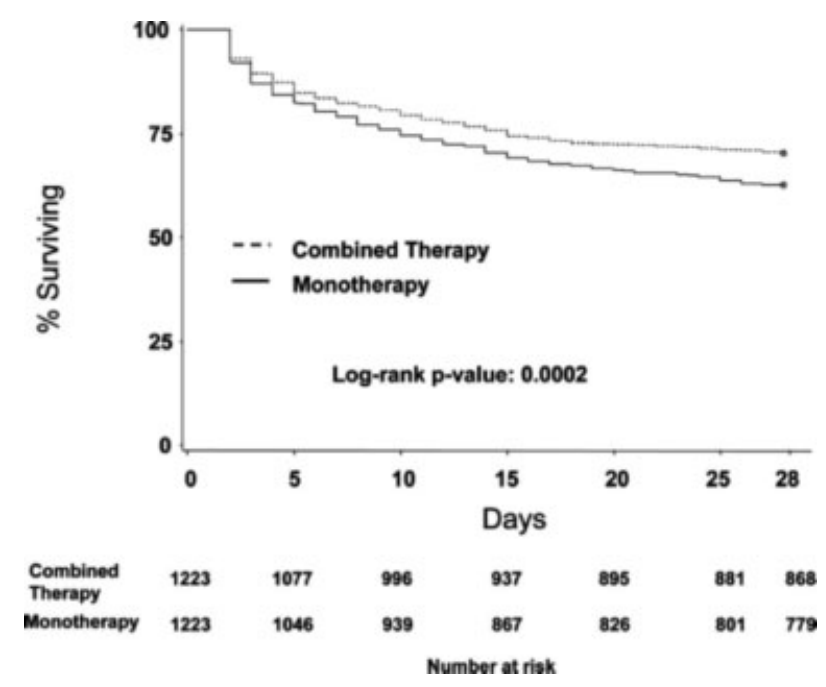

Fig. 10 Adjusted Cox proportional hazards of mortality associated with combination antibiotic therapy of septic shock. Reproduced with permission from Kumar et al. ${ }^{53}$

Combination therapy is useful under certain circumstances. For example, many experts would support the use of combination therapy for serious pseudomonal infections and for neutropenic sepsis. In addition, in situations where there is a significant level of bacterial multidrug resistance, the use of combination therapy may be warranted to ensure that likely pathogens are sensitive to at least one antibiotic.

If our composite model of septic shock with a microbial load-driven pathogenesis accurately reflects the pathophysiology of disease progression, only a few days of combination therapy (to hemodynamic stabilization and usually to organism identification) is required. Once hemodynamic stabilization is achieved, the microbial burden has been reduced to a subcritical threshold that should no longer leave the patient at risk for irreversible injury. Pending the publication of appropriate randomized trials, a strategy of several days of combination therapy for septic shock cases may be advisable.

\section{References}

1 Sands KE, Bates DW, Lanken PN, et al; Academic Medical Center Consortium Sepsis Project Working Group. Epidemiology of sepsis syndrome in 8 academic medical centers. JAMA 1997; 278(3):234-240

2 Brun-Buisson C, Doyon F, Carlet J, et al; French ICU Group for Severe Sepsis. Incidence, risk factors, and outcome of severe sepsis and septic shock in adults. A multicenter prospective study in intensive care units. JAMA 1995;274(12):968-974

3 Annane D, Aegerter P, Jars-Guincestre MC, Guidet B; CUB-Réa Network. Current epidemiology of septic shock: the CUB-Réa Network. Am J Respir Crit Care Med 2003;168(2):165-172

4 Finland M, Jones WF Jr, Barnes MW. Occurrence of serious bacterial infections since introduction of antibacterial agents. J Am Med Assoc 1959;170(18):2188-2197

5 Hemminki E, Paakkulainen A. The effect of antibiotics on mortality from infectious diseases in Sweden and Finland. Am J Public Health 1976;66(12):1180-1184
6 Kreger BE, Craven DE, McCabe WR. Gram-negative bacteremia. IV. Re-evaluation of clinical features and treatment in 612 patients. Am J Med 1980;68(3):344-355

7 Martin GS, Mannino DM, Eaton S, Moss M. The epidemiology of sepsis in the United States from 1979 through 2000. N Engl J Med 2003;348(16):1546-1554

8 Angus DC, Linde-Zwirble WT, Lidicker J, Clermont G, Carcillo J, Pinsky MR. Epidemiology of severe sepsis in the United States: analysis of incidence, outcome, and associated costs of care. Crit Care Med 2001;29(7):1303-1310

9 Eichacker PQ Natanson C. Increasing evidence that the risks of rhAPC may outweigh its benefits. Intensive Care Med 2007;33(3):396-399

10 Gårdlund B. Activated protein C (Xigris) treatment in sepsis: a drug in trouble. Acta Anaesthesiol Scand 2006;50(8):907-910 A

11 Kumar A. An alternate pathophysiologic paradigm of sepsis and septic shock: implications for optimizing antimicrobial therapy. Virulence 2014;5(1):80-97

12 Bone RC, Sibbald WJ, Sprung CL. The ACCP-SCCM consensus conference on sepsis and organ failure. Chest 1992;101(6):1481-1483

13 Levy MM, Fink MP, Marshall JC, et al; SCCM/ESICM/ACCP/ATS/SIS 2001 SCCM/ESICM/ACCP/ATS/SIS International Sepsis Definitions Conference. Crit Care Med 2003;31(4):1250-1256

14 van der Poll T, van Deventer SJH. Cytokines and anticytokines in the pathogenesis of sepsis. Infect Dis Clin North Am 1999;13(2): 413-426, ix

15 van der Poll T. Coagulation and inflammation. J Endotoxin Res 2001;7(4):301-304

16 Hotchkiss RS, Karl IE. The pathophysiology and treatment of sepsis. N Engl J Med 2003;348(2):138-150

17 Remick DG. Pathophysiology of sepsis. Am J Pathol 2007;170(5): 1435-1444

18 Freeman BD, Natanson C. Anti-inflammatory therapies in sepsis and septic shock. Expert Opin Investig Drugs 2000;9(7):1651-1663

19 Khatib R, Johnson LB, Fakih MG, et al. Persistence in Staphylococcus aureus bacteremia: incidence, characteristics of patients and outcome. Scand J Infect Dis 2006;38(1):7-14

20 Chowers MY, Gottesman B, Paul M, Weinberger M, Pitlik S, Leibovici L. Persistent bacteremia in the absence of defined intravascular foci: clinical significance and risk factors. Eur J Clin Microbiol Infect Dis 2003;22(10):592-596

21 Kullberg BJ, Sobel JD, Ruhnke M, et al. Voriconazole versus a regimen of amphotericin $B$ followed by fluconazole for candidaemia in non-neutropenic patients: a randomised non-inferiority trial. Lancet 2005;366(9495):1435-1442

22 Reboli AC, Rotstein C, Pappas PG, et al; Anidulafungin Study Group. Anidulafungin versus fluconazole for invasive candidiasis. N Engl J Med 2007;356(24):2472-2482

23 Levine DP, Fromm BS, Reddy BR. Slow response to vancomycin or vancomycin plus rifampin in methicillin-resistant Staphylococcus aureus endocarditis. Ann Intern Med 1991;115(9):674-680

24 Wiggers CJ. Experimental haemorrhage shock. In: Physiology of shock: The Commonwealth Fund. New York, NY: Harvard University Press; 1950:121-143

25 De Luca G, Suryapranata H, Ottervanger JP, Antman EM. Time delay to treatment and mortality in primary angioplasty for acute myocardial infarction: every minute of delay counts. Circulation 2004;109(10):1223-1225

26 Simoons ML, Serruys PW, vd Brand M, et al. Improved survival after early thrombolysis in acute myocardial infarction. A randomised trial by the Interuniversity Cardiology Institute in The Netherlands. Lancet 1985;2(8455):578-582

27 Sampalis JS, Lavoie A, Williams JI, Mulder DS, Kalina M. Impact of on-site care, prehospital time, and level of in-hospital care on survival in severely injured patients. J Trauma 1993;34(2): 252-261

28 Vallés J, Rello J, Ochagavía A, Garnacho J, Alcalá MA. Communityacquired bloodstream infection in critically ill adult patients: 
impact of shock and inappropriate antibiotic therapy on survival. Chest 2003;123(5):1615-1624

29 Ulloa L, Tracey KJ. The "cytokine profile": a code for sepsis. Trends Mol Med 2005;11(2):56-63

30 Wang H, Czura CJ, Tracey KJ. Lipid unites disparate syndromes of sepsis. Nat Med 2004;10(2):124-125

31 Simon PM, Delude RL, Lee M, et al; GenIMS Investigators. Duration and magnitude of hypotension and monocyte deactivation in patients with community-acquired pneumonia. Shock 2011; 36(6):553-559

32 Kumar A, Haery C, Paladugu B, et al. The duration of hypotension before the initiation of antibiotic treatment is a critical determinant of survival in a murine model of Escherichia coli septic shock: association with serum lactate and inflammatory cytokine levels. J Infect Dis 2006;193(2):251-258 A

33 Ovstebo R, Brandtzaeg P, Brusletto B, et al. Use of robotized DNA isolation and real-time PCR to quantify and identify close correlation between levels of Neisseria meningitidis DNA and lipopolysaccharides in plasma and cerebrospinal fluid from patients with systemic meningococcal disease. J Clin Microbiol 2004; 42(7):2980-2987

34 Lala HM, Mills GD, Barratt K, Bonning J, Manikkam NE, Martin D. Meningococcal disease deaths and the frequency of antibiotic administration delays. J Infect 2007;54(6):551-557

35 Rello J, Lisboa T, Lujan M, et al; DNA-Neumococo Study Group. Severity of pneumococcal pneumonia associated with genomic bacterial load. Chest 2009;136(3):832-840

36 DuPont HL, Spink WW. Infections due to gram-negative organisms: an analysis of 860 patients with bacteremia at the University of Minnesota Medical Center, 1958-1966. Medicine (Baltimore) 1969;48(4):307-332 A

37 Marra AR, Edmond MB, Forbes BA, Wenzel RP, Bearman GML. Time to blood culture positivity as a predictor of clinical outcome of Staphylococcus aureus bloodstream infection. J Clin Microbiol 2006;44(4):1342-1346

38 Khatib R, Riederer K, Saeed S, et al. Time to positivity in Staphylococcus aureus bacteremia: possible correlation with the source and outcome of infection. Clin Infect Dis 2005;41(5):594-598

39 Liao C-H, Lai C-C, Hsu M-S, et al. Correlation between time to positivity of blood cultures with clinical presentation and outcomes in patients with Klebsiella pneumoniae bacteraemia: prospective cohort study. Clin Microbiol Infect 2009;15(12): 1119-1125

40 Peralta G, Roiz MP, Sánchez MB, et al. Time-to-positivity in patients with Escherichia coli bacteraemia. Clin Microbiol Infect 2007;13(11):1077-1082

41 Martínez JA, Soto S, Fabrega A, et al. Relationship of phylogenetic background, biofilm production, and time to detection of growth in blood culture vials with clinical variables and prognosis associated with Escherichia coli bacteremia. J Clin Microbiol 2006;44(4):1468-1474

42 Chuang Y-C, Chang S-C, Wang W-K. Using the rate of bacterial clearance determined by real-time polymerase chain reaction as a timely surrogate marker to evaluate the appropriateness of antibiotic usage in critical patients with Acinetobacter baumannii bacteremia. Crit Care Med 2012;40(8):2273-2280

43 Ehrlich P. Address in pathology on chemiotherapy. : delivered before the Seventeenth International Congress of Medicine. BMJ 1913;2(2746):353-359

44 Ammerlaan H, Seifert H, Harbarth S, et al; European Practices of Infections with Staphylococcus aureus (SEPIA) Study Group. Adequacy of antimicrobial treatment and outcome of Staphylococcus aureus bacteremia in 9 Western European countries. Clin Infect Dis 2009;49(7):997-1005 A

45 Elhanan G, Sarhat M, Raz R. Empiric antibiotic treatment and the misuse of culture results and antibiotic sensitivities in patients with community-acquired bacteraemia due to urinary tract infection. J Infect 1997;35(3):283-288
46 Blot S, Vandewoude K, De Bacquer D, Colardyn F. Nosocomial bacteremia caused by antibiotic-resistant gram-negative bacteria in critically ill patients: clinical outcome and length of hospitalization. Clin Infect Dis 2002;34(12):1600-1606

47 Blot S, Depuydt P, Vogelaers D, et al. Colonization status and appropriate antibiotic therapy for nosocomial bacteremia caused by antibiotic-resistant gram-negative bacteria in an intensive care unit. Infect Control Hosp Epidemiol 2005;26(6):575-579

48 Haddy RI, Nadkarni DD, Mann BL, et al. Clostridial bacteremia in the community hospital. Scand J Infect Dis 2000;32(1):27-30

49 Kumar A, Ellis P, Arabi Y, et al; Cooperative Antimicrobial Therapy of Septic Shock Database Research Group. Initiation of inappropriate antimicrobial therapy results in a fivefold reduction of survival in human septic shock. Chest 2009;136(5):1237-1248

50 Romero-Vivas J, Rubio M, Fernandez C, Picazo JJ. Mortality associated with nosocomial bacteremia due to methicillin-resistant Staphylococcus aureus. Clin Infect Dis 1995;21(6):1417-1423

51 Nguyen MH, Peacock JE Jr, Tanner DC, et al. Therapeutic approaches in patients with candidemia. Evaluation in a multicenter, prospective, observational study. Arch Intern Med 1995; 155(22):2429-2435

52 Garnacho-Montero J, García-Cabrera E, Diaz-Martín A, et al. Determinants of outcome in patients with bacteraemic pneumococcal pneumonia: importance of early adequate treatment. Scand J Infect Dis 2010;42(3):185-192

53 Kumar A, Zarychanski R, Light B, et al; Cooperative Antimicrobial Therapy of Septic Shock (CATSS) Database Research Group. Early combination antibiotic therapy yields improved survival compared with monotherapy in septic shock: a propensity-matched analysis. Crit Care Med 2010;38(9):1773-1785

54 Kollef MH. Broad-spectrum antimicrobials and the treatment of serious bacterial infections: getting it right up front. Clin Infect Dis 2008;47(1, Suppl 1):S3-S13

55 Paul M, Shani V, Muchtar E, Kariv G, Robenshtok E, Leibovici L. Systematic review and meta-analysis of the efficacy of appropriate empiric antibiotic therapy for sepsis. Antimicrob Agents Chemother 2010;54(11):4851-4863

56 Kollef MH, Sherman G, Ward S, Fraser VJ. Inadequate antimicrobial treatment of infections: a risk factor for hospital mortality among critically ill patients. Chest 1999;115(2):462-474

57 Kollef MH, Morrow LE, Niederman MS, et al. Clinical characteristics and treatment patterns among patients with ventilatorassociated pneumonia. Chest 2006;129(5):1210-1218

58 Singh N, Rogers P, Atwood CW, Wagener MM, Yu VL. Shortcourse empiric antibiotic therapy for patients with pulmonary infiltrates in the intensive care unit. A proposed solution for indiscriminate antibiotic prescription. Am J Respir Crit Care Med 2000;162(2, Pt 1):505-511

59 Aarts M-A, Brun-Buisson C, Cook DJ, et al. Antibiotic management of suspected nosocomial ICU-acquired infection: does prolonged empiric therapy improve outcome? Intensive Care Med 2007; 33(8):1369-1378

60 Joung MK, Lee JA, Moon S-Y, et al. Impact of de-escalation therapy on clinical outcomes for intensive care unit-acquired pneumonia. Crit Care 2011;15(2):R79

61 Anderson DJ, Engemann JJ, Harrell LJ, Carmeli Y, Reller LB, Kaye KS. Predictors of mortality in patients with bloodstream infection due to ceftazidime-resistant Klebsiella pneumoniae. Antimicrob Agents Chemother 2006;50(5):1715-1720

62 Lodise TP Jr, Patel N, Kwa A, et al. Predictors of 30-day mortality among patients with Pseudomonas aeruginosa bloodstream infections: impact of delayed appropriate antibiotic selection. Antimicrob Agents Chemother 2007;51(10):3510-3515

63 Mathevon T, Souweine B, Traoré O, Aublet B, Caillaud D. ICUacquired nosocomial infection: impact of delay of adequate antibiotic treatment. Scand J Infect Dis 2002;34(11):831-835

64 Morrell M, Fraser VJ, Kollef MH. Delaying the empiric treatment of candida bloodstream infection until positive blood culture results 
are obtained: a potential risk factor for hospital mortality. Antimicrob Agents Chemother 2005;49(9):3640-3645

65 Zahar J-R, Azoulay E, Klement E, et al. Delayed treatment contributes to mortality in ICU patients with severe active pulmonary tuberculosis and acute respiratory failure. Intensive Care Med 2001;27(3):513-520

66 Gaieski DF, Mikkelsen ME, Band RA, et al. Impact of time to antibiotics on survival in patients with severe sepsis or septic shock in whom early goal-directed therapy was initiated in the emergency department. Crit Care Med 2010;38(4):1045-1053

67 Lueangarun S, Leelarasamee A. Impact of inappropriate empiric antimicrobial therapy on mortality of septic patients with bacteremia: a retrospective study. Interdiscip Perspect Infect Dis 2012;2012(2012):765205

68 Lin MY, Weinstein RA, Hota B. Delay of active antimicrobial therapy and mortality among patients with bacteremia: impact of severe neutropenia. Antimicrob Agents Chemother 2008; 52(9):3188-3194

69 Corona A, Bertolini G, Lipman J, Wilson AP, Singer M. Antibiotic use and impact on outcome from bacteraemic critical illness: the Bacteraemia Study in Intensive Care (BASIC). J Antimicrob Chemother 2010;65(6):1276-1285

70 Silber SH, Garrett C, Singh R, et al. Early administration of antibiotics does not shorten time to clinical stability in patients with moderate-to-severe community-acquired pneumonia. Chest 2003;124(5):1798-1804

71 Kaasch AJ, Rieg S, Kuetscher J, et al; preSABATO Study Group. Delay in the administration of appropriate antimicrobial therapy in Staphylococcus aureus bloodstream infection: a prospective multicenter hospital-based cohort study. Infection 2013;41(5):979-985

72 Kumar A, Roberts D, Wood KE, et al. Duration of hypotension before initiation of effective antimicrobial therapy is the critical determinant of survival in human septic shock. Crit Care Med 2006;34(6):1589-1596

73 Lodise TP, McKinnon PS, Swiderski L, Rybak MJ. Outcomes analysis of delayed antibiotic treatment for hospital-acquired Staphylococcus aureus bacteremia. Clin Infect Dis 2003;36(11):1418-1423

74 Menéndez R, Torres A, Reyes S, et al. Initial management of pneumonia and sepsis: factors associated with improved outcome. Eur Respir J 2012;39(1):156-162

75 Iregui M, Ward S, Sherman G, Fraser VJ, Kollef MH. Clinical importance of delays in the initiation of appropriate antibiotic treatment for ventilator-associated pneumonia. Chest 2002; 122(1):262-268

76 Aronin SI, Peduzzi P, Quagliarello VJ. Community-acquired bacterial meningitis: risk stratification for adverse clinical outcome and effect of antibiotic timing. Ann Intern Med 1998;129(11):862-869

77 Ferrer R, Artigas A, Suarez D, et al; Edusepsis Study Group. Effectiveness of treatments for severe sepsis: a prospective, multicenter, observational study. Am J Respir Crit Care Med 2009;180(9):861-866

78 Dellinger RP, Levy MM, Carlet JM, et al; International Surviving Sepsis Campaign Guidelines Committee; American Association of Critical-Care Nurses; American College of Chest Physicians; American College of Emergency Physicians; Canadian Critical Care Society; European Society of Clinical Microbiology and Infectious Diseases; European Society of Intensive Care Medicine; European Respiratory Society; International Sepsis Forum; Japanese Association for Acute Medicine; Japanese Society of Intensive Care Medicine; Society of Critical Care Medicine; Society of Hospital Medicine; Surgical Infection Society; World Federation of Societies of Intensive and Critical Care Medicine. Surviving Sepsis Campaign: international guidelines for management of severe sepsis and septic shock: 2008. Crit Care Med 2008;36(1):296-327

79 Taccone FS, Laterre P-F, Dugernier T, et al. Insufficient $\beta$-lactam concentrations in the early phase of severe sepsis and septic shock. Crit Care 2010;14(4):R126
80 Chelluri L, Jastremski MS. Inadequacy of standard aminoglycoside loading doses in acutely ill patients. Crit Care Med 1987;15(12): 1143-1145

81 Ocampos-Martinez E, Penaccini L, Scolletta S, et al. Determinants of early inadequate vancomycin concentrations during continuous infusion in septic patients. Int J Antimicrob Agents 2012; 39(4):332-337

82 Varghese JM, Roberts JA, Lipman J. Antimicrobial pharmacokinetic and pharmacodynamic issues in the critically ill with severe sepsis and septic shock. Crit Care Clin 2011;27(1):19-34

83 Pea F, Viale P. Bench-to-bedside review: Appropriate antibiotic therapy in severe sepsis and septic shock-does the dose matter? Crit Care 2009;13(3):214

84 Calandra T, Glauser MP. Immunocompromised animal models for the study of antibiotic combinations. Am J Med 1986;80 (5C):45-52

85 Finberg RW, Moellering RC, Tally FP, et al. The importance of bactericidal drugs: future directions in infectious disease. Clin Infect Dis 2004;39(9):1314-1320

86 Pankey GA, Sabath LD. Clinical relevance of bacteriostatic versus bactericidal mechanisms of action in the treatment of Grampositive bacterial infections. Clin Infect Dis 2004;38(6):864-870

87 Lepper MH, Dowling HF; MH L. Treatment of pneumococcic meningitis with penicillin compared with penicillin plus aureomycin; studies including observations on an apparent antagonism between penicillin and aureomycin. AMA Arch Intern Med 1951;88(4):489-494

88 Weinstein MP, Stratton CW, Ackley A, et al. Multicenter collaborative evaluation of a standardized serum bactericidal test as a prognostic indicator in infective endocarditis. Am J Med 1985; 78(2):262-269

89 Mylonakis E, Calderwood SB. Infective endocarditis in adults. N Engl J Med 2001;345(18):1318-1330

90 Weinstein MP, Stratton CW, Hawley HB, Ackley A, Reller LB. Multicenter collaborative evaluation of a standardized serum bactericidal test as a predictor of therapeutic efficacy in acute and chronic osteomyelitis. Am J Med 1987;83(2):218-222

91 Sculier JP, Klastersky J. Significance of serum bactericidal activity in gram-negative bacillary bacteremia in patients with and without granulocytopenia. Am J Med 1984;76(3):429-435

92 Small PM, Chambers HF. Vancomycin for Staphylococcus aureus endocarditis in intravenous drug users. Antimicrob Agents Chemother 1990;34(6):1227-1231

93 Khatib R, Saeed S, Sharma M, Riederer K, Fakih MG, Johnson LB. Impact of initial antibiotic choice and delayed appropriate treatment on the outcome of Staphylococcus aureus bacteremia. Eur J Clin Microbiol Infect Dis 2006;25(3):181-185

$94 \mathrm{Kim} \mathrm{S-H,} \mathrm{Kim} \mathrm{K-H,} \mathrm{Kim} \mathrm{H-B,} \mathrm{et} \mathrm{al.} \mathrm{Outcome} \mathrm{of} \mathrm{vancomycin}$ treatment in patients with methicillin-susceptible Staphylococcus aureus bacteremia. Antimicrob Agents Chemother 2008; 52(1):192-197

95 Rubinstein E, Cammarata S, Oliphant T, Wunderink R; Linezolid Nosocomial Pneumonia Study Group. Linezolid (PNU-100766) versus vancomycin in the treatment of hospitalized patients with nosocomial pneumonia: a randomized, double-blind, multicenter study. Clin Infect Dis 2001;32(3):402-412

96 Fagon J, Patrick H, Haas DW, et al; Nosocomial Pneumonia Group. Treatment of gram-positive nosocomial pneumonia. Prospective randomized comparison of quinupristin/dalfopristin versus vancomycin. Am J Respir Crit Care Med 2000;161(3, Pt 1):753-762

97 Fowler VG Jr, Boucher HW, Corey GR, et al; S. aureus Endocarditis and Bacteremia Study Group. Daptomycin versus standard therapy for bacteremia and endocarditis caused by Staphylococcus aureus. N Engl J Med 2006;355(7):653-665

98 McKinnon PS, Paladino JA, Schentag JJ. Evaluation of area under the inhibitory curve (AUIC) and time above the minimum inhibitory concentration $(\mathrm{T}>\mathrm{MIC})$ as predictors of outcome for 
cefepime and ceftazidime in serious bacterial infections. Int J Antimicrob Agents 2008;31(4):345-351

99 Crandon JL, Bulik CC, Kuti JL, Nicolau DP. Clinical pharmacodynamics of cefepime in patients infected with Pseudomonas aeruginosa. Antimicrob Agents Chemother 2010;54(3): 1111-1116

100 Chytra I, Stepan M, Benes J, et al. Clinical and microbiological efficacy of continuous versus intermittent application of meropenem in critically ill patients: a randomized open-label controlled trial. Crit Care 2012;16(3):R113

101 Lorente L, Jiménez A, Martín MM, Iribarren JL, Jiménez JJ, Mora ML. Clinical cure of ventilator-associated pneumonia treated with piperacillin/tazobactam administered by continuous or intermittent infusion. Int J Antimicrob Agents 2009;33(5):464-468

102 Lorente L, Jiménez A, Palmero S, et al. Comparison of clinical cure rates in adults with ventilator-associated pneumonia treated with intravenous ceftazidime administered by continuous or intermittent infusion: a retrospective, nonrandomized, openlabel, historical chart review. Clin Ther 2007;29(11):2433-2439

103 Lorente L, Lorenzo L, Martín MM, Jiménez A, Mora ML. Meropenem by continuous versus intermittent infusion in ventilatorassociated pneumonia due to gram-negative bacilli. Ann Pharmacother 2006;40(2):219-223

104 Lodise TP Jr, Lomaestro B, Drusano GL. Piperacillin-tazobactam for Pseudomonas aeruginosa infection: clinical implications of an extended-infusion dosing strategy. Clin Infect Dis 2007;44(3): 357-363

105 Kasiakou SK, Sermaides GJ, Michalopoulos A, Soteriades ES, Falagas ME. Continuous versus intermittent intravenous administration of antibiotics: a meta-analysis of randomised controlled trials. Lancet Infect Dis 2005;5(9):581-589

106 Roberts JA, Webb S, Paterson D, Ho KM, Lipman J. A systematic review on clinical benefits of continuous administration of betalactam antibiotics. Crit Care Med 2009;37(6):2071-2078

107 Scaglione F, Mouton JW, Mattina R, Fraschini F. Pharmacodynamics of levofloxacin and ciprofloxacin in a murine pneumonia model: peak concentration/MIC versus area under the curve/MIC ratios. Antimicrob Agents Chemother 2003;47(9): 2749-2755

108 Winterboer TM, Lecci KA, Olsen KM. Continuing education: alternative approaches to optimizing antimicrobial pharmacodynamics in critically ill patients. J Pharm Pract 2010;23(1):6-18

109 Forrest A, Nix DE, Ballow CH, Goss TF, Birmingham MC, Schentag JJ. Pharmacodynamics of intravenous ciprofloxacin in seriously ill patients. Antimicrob Agents Chemother 1993;37(5):1073-1081

110 Moore RD, Smith CR, Lietman PS. Association of aminoglycoside plasma levels with therapeutic outcome in gram-negative pneumonia. Am J Med 1984;77(4):657-662

111 Moore RD, Smith CR, Lietman PS. The association of aminoglycoside plasma levels with mortality in patients with gram-negative bacteremia. J Infect Dis 1984;149(3):443-448

112 Moore RD, Lietman PS, Smith CR. Clinical response to aminoglycoside therapy: importance of the ratio of peak concentration to minimal inhibitory concentration. J Infect Dis 1987;155(1): 93-99

113 Kullar R, Davis SL, Levine DP, Rybak MJ. Impact of vancomycin exposure on outcomes in patients with methicillin-resistant Staphylococcus aureus bacteremia: support for consensus guidelines suggested targets. Clin Infect Dis 2011;52(8):975-981

114 Moise-Broder PA, Forrest A, Birmingham MC, Schentag JJ. Pharmacodynamics of vancomycin and other antimicrobials in patients with Staphylococcus aureus lower respiratory tract infections. Clin Pharmacokinet 2004;43(13):925-942

115 Zelenitsky S, Rubinstein E, Ariano R, et al; Cooperative Antimicrobial Therapy of Septic Shock-CATSS Database Research Group. Vancomycin pharmacodynamics and survival in patients with methicillin-resistant Staphylococcus aureus-associated septic shock. Int J Antimicrob Agents 2013;41(3):255-260
116 Chow JW, Yu VL. Combination antibiotic therapy versus monotherapy for gram-negative bacteraemia: a commentary. Int J Antimicrob Agents 1999;11(1):7-12 A

117 Micek ST, Welch EC, Khan J, et al. Empiric combination antibiotic therapy is associated with improved outcome against sepsis due to Gram-negative bacteria: a retrospective analysis. Antimicrob Agents Chemother 2010;54(5):1742-1748

118 Giamarellou H, Zissis NP, Tagari G, Bouzos J. In vitro synergistic activities of aminoglycosides and new beta-lactams against multiresistant Pseudomonas aeruginosa. Antimicrob Agents Chemother 1984;25(4):534-536

119 Klastersky J, Zinner SH. Synergistic combinations of antibiotics in gram-negative bacillary infections. Rev Infect Dis 1982;4(2): 294-301

120 Mouton JW. Combination therapy as a tool to prevent emergence of bacterial resistance. Infection 1999;27(Suppl 2):S24-S28

121 Anderson ET, Young LS, Hewitt WL. Antimicrobial synergism in the therapy of gram-negative rod bacteremia. Chemotherapy 1978;24(1):45-54

122 Giamarellou H. Aminoglycosides plus beta-lactams against gramnegative organisms. Evaluation of in vitro synergy and chemical interactions. Am J Med 1986;80(6B):126-137

123 Kluge RM, Standiford HC, Tatem B, et al. Comparative activity of tobramycin, amikacin, and gentamicin alone and with carbenicillin against Pseudomonas aeruginosa. Antimicrob Agents Chemother 1974;6(4):442-446 A

124 Neu HC. Synergy and antagonism of fluoroquinolones with other classes of antimicrobial agents. Drugs 1993;45(Suppl 3):54-58

125 Pohlman JK, Knapp CC, Ludwig MD, Washington JA. Timed killing kinetic studies of the interaction between ciprofloxacin and $\beta$ lactams against gram-negative bacilli. Diagn Microbiol Infect Dis 1996;26(1):29-33

126 MacGowan AR, Bowker K, Bedford KA, Holt HA, Reeves DS. Synergy testing of macrolide combinations using the chequerboard technique. J Antimicrob Chemother 1993;32(6):913-915

127 Manian FA, Meyer L, Jenne J, Owen A, Taff T. Loss of antimicrobial susceptibility in aerobic gram-negative bacilli repeatedly isolated from patients in intensive-care units. Infect Control Hosp Epidemiol 1996;17(4):222-226

128 Safdar N, Handelsman J, Maki DG. Does combination antimicrobial therapy reduce mortality in Gram-negative bacteraemia? A meta-analysis. Lancet Infect Dis 2004;4(8):519-527

129 Marcus R, Paul M, Elphick H, Leibovici L. Clinical implications of $\beta$ lactam-aminoglycoside synergism: systematic review of randomised trials. Int J Antimicrob Agents 2011;37(6):491-503

130 Paul M, Benuri-Silbiger I, Soares-Weiser K, Leibovici L. Beta lactam monotherapy versus beta lactam-aminoglycoside combination therapy for sepsis in immunocompetent patients: systematic review and meta-analysis of randomised trials. BMJ 2004;328(7441):668

131 Paul M, Silbiger I, Grozinsky S, Soares-Weiser K, Leibovici L. Beta lactam antibiotic monotherapy versus beta lactam-aminoglycoside antibiotic combination therapy for sepsis. Cochrane Database Syst Rev 2006;(1):CD003344

132 Paul M, Lador A, Grozinsky-Glasberg S, Leibovici L. Beta lactam antibiotic monotherapy versus beta lactam-aminoglycoside antibiotic combination therapy for sepsis. Cochrane Database Syst Rev 2014;1:CD003344

133 Paul M, Soares-Weiser K, Leibovici L. Beta lactam monotherapy versus beta lactam-aminoglycoside combination therapy for fever with neutropenia: systematic review and meta-analysis. BMJ 2003;326(7399):1111

134 Waterer GW, Somes GW, Wunderink RG. Monotherapy may be suboptimal for severe bacteremic pneumococcal pneumonia. Arch Intern Med 2001;161(15):1837-1842

135 Baddour LM, Yu VL, Klugman KP, et al; International Pneumococcal Study Group. Combination antibiotic therapy lowers mortality among severely ill patients with pneumococcal bacteremia. Am J Respir Crit Care Med 2004;170(4):440-444 
136 Rodríguez A, Mendia A, Sirvent J-M, et al; CAPUCI Study Group. Combination antibiotic therapy improves survival in patients with community-acquired pneumonia and shock. Crit Care Med 2007;35(6):1493-1498

137 Hilf M, Yu VL, Sharp J, Zuravleff JJ, Korvick JA, Muder RR. Antibiotic therapy for Pseudomonas aeruginosa bacteremia: outcome correlations in a prospective study of 200 patients. Am J Med 1989; 87(5):540-546

138 Korvick JA, Bryan CS, Farber B, et al. Prospective observational study of Klebsiella bacteremia in 230 patients: outcome for antibiotic combinations versus monotherapy. Antimicrob Agents Chemother 1992;36(12):2639-2644 A

139 Kumar A, Safdar N, Kethireddy S, Chateau D. A survival benefit of combination antibiotic therapy for serious infections associated with sepsis and septic shock is contingent only on the risk of death: a meta-analytic/meta-regression study. Crit Care Med 2010;38(8):1651-1664

140 Abad CL, Kumar A, Safdar N. Antimicrobial therapy of sepsis and septic shock-when are two drugs better than one? Crit Care Clin 2011;27(2):e1-e27

141 Brunkhorst FM, Oppert M, Marx G, et al; German Study Group Competence Network Sepsis (SepNet). Effect of empirical treatment with moxifloxacin and meropenem vs meropenem on sepsis-related organ dysfunction in patients with severe sepsis: a randomized trial. JAMA 2012;307(22):2390-2399

142 Delannoy P-Y, Boussekey N, Devos P, et al. Impact of combination therapy with aminoglycosides on the outcome of ICU-acquired bacteraemias. Eur J Clin Microbiol Infect Dis 2012;31(9):2293-2299 